\title{
Gelatinolytic proteinase activities in human seminal plasma*
}

\author{
H.-Z. Yin $\dagger \ddagger$, M. M. Vogel $\dagger$, M. Schneider $\ddagger$, C. Ercole $\downarrow \ddagger$, G. Zhang $\ddagger$, \\ A. A. Sinha† $\$$ and M. J. Wilson†ף \\ $\dagger V A$ Medical Center and Departments of $\ddagger$ Urologic Surgery, §Genetics and Cell Biology, and \\ $\uparrow$ Laboratory Medicine and Pathology, University of Minnesota, Minneapolis, MN 55417, USA
}

\begin{abstract}
Summary. Proteinase activities in human seminal plasma were detected using gelatincontaining sodium dodecyl sulphate-polyacrylamide gel electrophoresis zymography. Three prominent bands of activity of $M_{\mathrm{r}} 60000,66000$ and 90000 were oberved as well as 9 other bands of less intensity (34000-158000). These proteinases were dependent upon calcium for optimal activity, did not hydrolyse casein, and were predominantly in the soluble portion of seminal plasma. Examination of seminal plasma of men with different sperm concentrations, split ejaculates, and prostatic secretions indicated that the prostate gland was a source of most of these activities. Proteinase activities of $M_{\mathrm{r}} 34000,37000,82000$ and 120000 were expressed more frequently in seminal plasma from normozoospermic men than from seminal plasma of oligo- or azoospermic men, indicating that they may also arise from spermatozoa in the semen sample. The proteinases of $M_{\mathrm{r}} 60000$ and 66000 were found in all seminal plasmas whereas there was variation in the expression of the other molecular forms of enzyme, even in the normozoospermic samples. There are multiple forms of gelatinolytic proteinase activities in human seminal plasma which appear to arise from multiple sources in the reproductive tract including the Cowper's/urethral glands, the prostate gland, seminal vesicle and/or spermatozoa. Their function(s) in semen remains to be established.
\end{abstract}

Keywords: seminal plasma; human; proteinase

\section{Introduction}

The phenomenon of semen coagulation is a well developed process in many animal species (Mann \& Lutwak-Mann, 1981). Human semen coagulates immediately at ejaculation and subsequently liquefies within 5-20 min (Tauber et al., 1980). Coagulation of semen has been most extensively studied in rodents in which a copulatory plug is formed. The generation of the matrix of the plug is brought about by the production of cross-linkages via isodipeptide bonds of $\varepsilon$ - $(\gamma$-glutamyl $)$ lysine residues in several (perhaps 5-7) basic proteins from the secretion of the seminal vesicles. This process is calcium-dependent and is catalysed by transglutaminases introduced into semen by the coagulating glands (Williams-Ashman et al., 1980). The coagulating proteins of human semen are also secreted by the seminal vesicles. However, the resultant clot matrix, unlike that of the rodent, appears to be maintained by non-covalent bonding since it can be dissolved by denaturation (e.g. 2-3 M-guanidine- $\mathrm{HCl}$ ). Disulphide linkages are present but there is disagreement whether their disruption alone dissolves the clot (Chaistitvanich \& Boonsaeng, 1983; Lilja \& Laurell, 1985). Also in distinction to rodent semen coagulation, no transglutaminase activities have been detected in human seminal or prostatic fluids (Lilja \& Laurell, 1985).

\footnotetext{
*Reprint requests to: Dr Michael Wilson, Research Service (151), VA Medical Center, One Veterans Drive, Minneapolis, MN 55417, USA.
} 
Liquefaction of human semen occurs in a $\mathrm{pH}$ range of $6 \cdot 8-8 \cdot 8$ and is thought to be mediated by hydrolases primarily contributed by the prostate. The liquefaction process is characterized by the rapid decrease in molecular size of the prominent vesicular proteins in semen (Balerna et al., 1984; Rui et al., 1984; Lilja \& Laurell, 1985; Boonsaeng, 1986; McGee \& Herr, 1987). Several proteinases have been postulated to mediate the breakdown of the human seminal coagulum. These enzymes include plasminogen activator (Harvey, 1949; Rasmussen \& Albrechtsen, 1960; Hisazumi, 1970; Liedholm et al., 1973), collagenase-like peptidase (Lukac \& Koren, 1979), and seminin (Syner et al., 1975; Tauber et al., 1980). Prostatic specific antigen has also been shown to cleave the seminal vesicle secretory proteins of high molecular weight that form the coagulum (Lilja, 1985; McGee \& Herr, 1988). In addition to these proteinase activities, human seminal fluid also contains several proteinase inhibitors which could affect the expression of proteolytic activity. Low molecular weight cysteine proteinase inhibitors $\left(M_{\mathrm{r}} 11000\right.$ and 16000) and acid-stable inhibitors $\left(M_{\mathrm{r}} 6500\right.$ and 11000 ) of accessory gland origin have been characterized (Schiessler et al., 1976; Minakata et al., 1986). The large molecular weight proteinase inhibitors $\alpha 1$-antitrypsin and $\alpha 1$-antichymotrypsin are found in seminal fluid but they appear to be derived from serum (Schill, 1976).

The purpose of this study was to examine proteinase activities of human seminal plasma that could hydrolyse matrix-forming proteins.

\section{Materials and Methods}

Materials. Gelatin, acrylamide, and bis-acrylamide were obtained from Bio-Rad (Richmond, CA., USA). All other chemicals were of the highest grade available.

Methods. Semen samples were obtained by masturbation from donors or men attending the Male Infertility Clinic, University of Minnesota Hospital. Semen samples from 60 men were used. These semen samples were collected after a minimum abstinence period of 3 days. The azoospermic samples included 2 from men with vasectomies, 4 from men with obstruction of the vas deferens or epididymis, and 6 from men with a lack of spermatogenesis due to atrophy of the germinal epithelium or spermatocytic arrest (includes one patient taking anabolic steroids and another receiving chemotherapy for Hodgkins disease). Prostatic fluids were collected by prostate massage from men with chronic, non-bacterial prostatitis at the Urology Clinic of the Minneapolis VA Medical Center. The numbers of spermatozoa in non-vasectomy semen samples were determined using the Makler chamber, and the percentages of viable, motile and abnormal forms of spermatozoa were determined by microscopic examination after eosin-nigrosin staining (Amelar \& Dubin, 1977). Semen samples were maintained for 30-60 $\mathrm{min}$ at room temperature to perform the above examinations and then centrifuged at $960 \mathrm{~g}$ for $15 \mathrm{~min}$ at room temperature to sediment spermatozoa. The seminal plasma was removed and frozen at $-80^{\circ} \mathrm{C}$. In some cases the seminal plasma samples were centrifuged further at $105000 \mathrm{~g}$ for $60 \mathrm{~min}$ at $4^{\circ} \mathrm{C}$. The supernatant was removed and was referred to as the soluble portion of seminal plasma. The membrane pellet was resuspended in $0.25 \mathrm{M}$-sucrose and frozen at $-80^{\circ} \mathrm{C}$.

Three samples were collected by the split-ejaculate technique. The donors were asked to collect each orgasmic contraction into individual tubes (9); any additional contractions beyond the ninth were collected into the ninth tube. These samples were maintained at room temperature for $30 \mathrm{~min}$ and then centrifuged at $960 \mathrm{~g}$ for $15 \mathrm{~min}$ at room temperature. The supernatants were removed and frozen at $-80^{\circ} \mathrm{C}$.

Protease zymography. Aliquants of seminal plasma or prostatic secretion were subjected to electrophoresis in gelatin-containing polyacrylamide ( $8 \%$ acrylamide) gels in the presence of sodium dodecyl sulphate under nonreducing conditions (Heussen \& Dowdle, 1980; Wilson et al., 1988). The gels were electrophoresed overnight at $15^{\circ} \mathrm{C}$ and $8 \mathrm{~mA}$ constant current. After electrophoresis, the gels were rinsed with distilled water and then washed with gentle shaking at room temperature with $0.25 \%$ Triton X-100 ( 3 changes) for $2 \mathrm{~h}$. The gel slabs were rinsed in distilled water, incubated in $50 \mathrm{~mm}$-Tris- $\mathrm{HCl}\left(\mathrm{pH} 8.0\right.$ ) containing $50 \mathrm{mM}^{-\mathrm{CaCl}_{2}}$ (2 changes) at $37^{\circ} \mathrm{C}$ for $18-20 \mathrm{~h}$ (Hume et al., 1987) and subsequently stained with amido black. Areas of proteolysis appear as clear zones against a blue background. In preliminary experiments, proteinase patterns in fresh seminal plasma were compared with those of the same sample after freezing; no differences were found (data not shown). Seminal plasma used in these studies was routinely stored frozen before zymography.

Molecular mass determinations were made with reference to protein standards co-electrophoresed in these gels. These standards (Diversified Biotech, Newton Center, MA., USA) were prestained and included phosphorylase B, 95 500; glutamate dehydrogenase, 55000 ; ovalbumin, 43000 ; lactic dehydrogenase, 36000 ; and carbonic anhydrase, 29000 .

Gel filtration chromatography. Seminal plasma soluble fraction $(2.0 \mathrm{ml})$ was chromatographed on a $1.5 \times 95.5 \mathrm{~cm}$ column of Sephacryl S-200 HR (Pharmacia, Piscataway, NJ, USA) which had been equilibrated with $0.05 \mathrm{M}-\mathrm{Tris}-\mathrm{HCl}$ (pH 7.5) containing $0.1 \mathrm{M}-\mathrm{NaCl}$. The column was eluted at a rate of $10 \mathrm{ml} / \mathrm{h}$ and $1.95-\mathrm{ml}$ fractions were collected. 
Protease assay. The casein hydrolysis method to measure seminin activity as described by Syner \& Moghissi (1972) was used with some modification. The final reaction volume was $0.40 \mathrm{ml}$ and contained $0.1 \mathrm{M}-\mathrm{Tris}-\mathrm{HCl}(\mathrm{pH} 7.5)$ and $2 \mathrm{mg}$ casein. The reaction was started by the addition of $0.10 \mathrm{ml}$ of column fraction and was incubated for $1 \mathrm{~h}$ at $37^{\circ} \mathrm{C}$ before termination by addition of $0.4 \mathrm{ml}$ cold $10 \%(\mathrm{w} / \mathrm{v})$ trichloroacetic acid. The tubes were centrifuged at $960 \mathrm{~g}$ for $10 \mathrm{~min}$ after standing on ice for $20 \mathrm{~min}$. A $0 \cdot 20$ - $\mathrm{ml}$ sample of the supernatant was used in the colorimetric determination (Lowry et al., 1951) of soluble hydrolysis products using the Folin Ciocalteau phenol reagent (Sigma Chemical Co., St Louis, MO, USA). The absorbance at $750 \mathrm{~nm}$ was measured.

\section{Results}

\section{Properties of gelatinolytic proteinases}

Seminal plasma contains several proteinase activities that are capable of hydrolysing gelatin. The bands of activity observed in a gelatin-polyacrylamide gel were labelled sequentially by numbers from the lowest molecular weight to the highest (Fig. 1). Three prominent bands of activity of $M_{\mathrm{r}} 60000,66000$ and 90000 (bands 3, 4, and 7) were detected as well as bands of less activity or varied intensity at $M_{\mathrm{r}}$ values of approximately $34000,37000,71000,82000,105000$, $110000,120000,140000$ and 158000 . The gels in this study were incubated to maximize the activity in individual proteinase bands to optimize their detection and therefore were examined for qualitative determinations since strict quantitative analyses cannot be made. The relative activity of

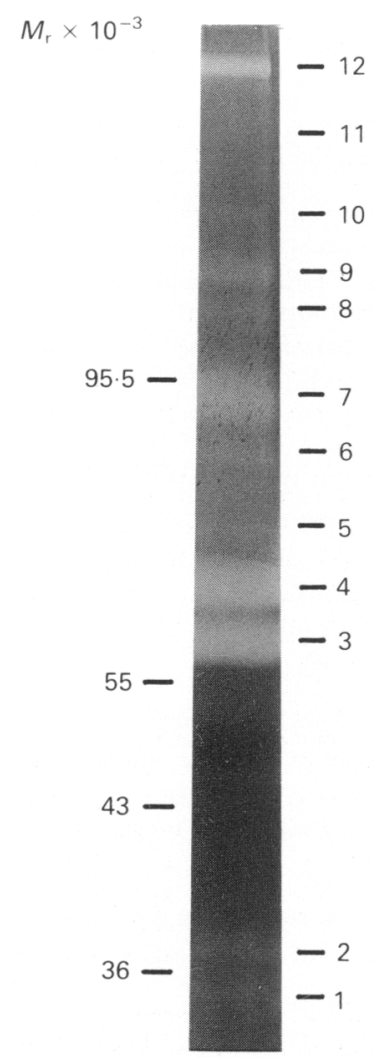

Fig. 1. Zymogram of gelatinolytic activities in human seminal plasma. Seminal plasma $(10 \mu \mathrm{l})$ from a man with normal sperm numbers $\left(136 \times 10^{6} / \mathrm{ml}\right)$ was electrophoresed in an $8 \%$ SDS polyacrylamide gelatin-containing gel. Twelve bands of proteinase activities were detected and were numbered 1-12. The notation of band number in this figure was used for evaluation of other zymograms. 
(b)

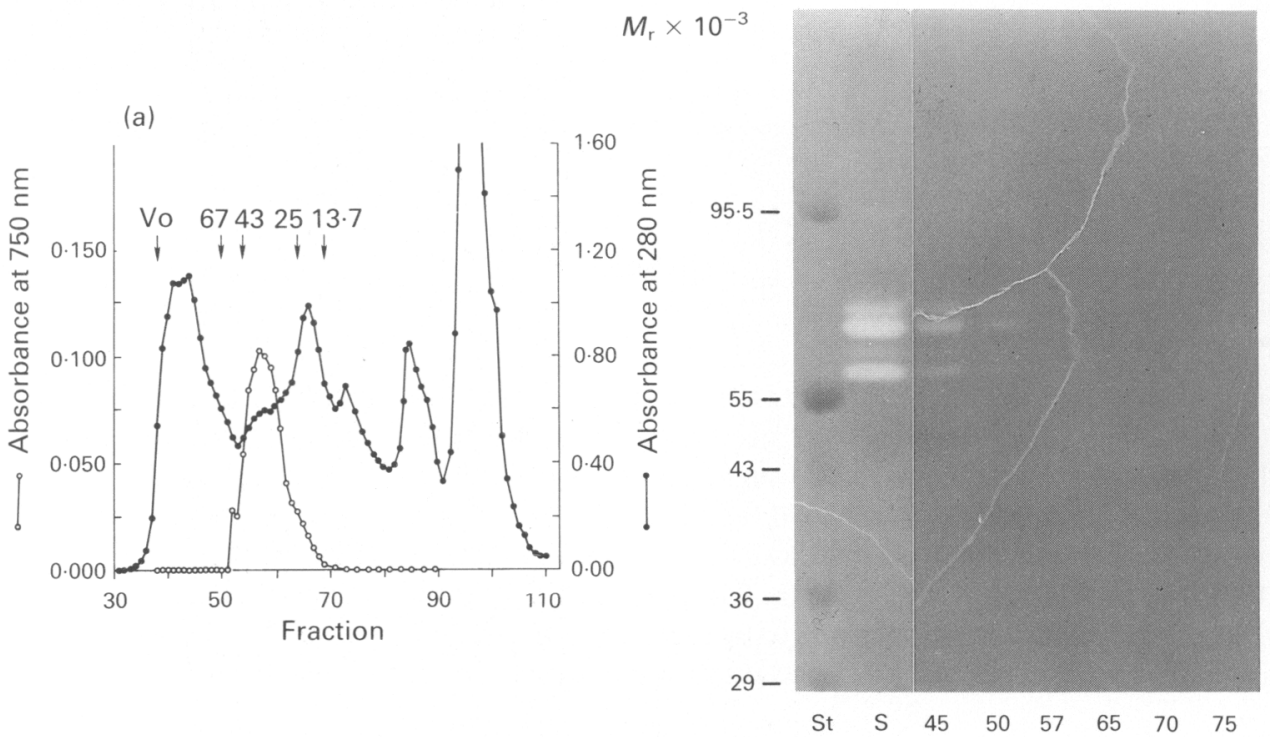

Fig. 2. Separation of gelatinolytic and caseinolytic proteinase activities by gel filtration chromatography. (a) Gel filtration chromatography of the soluble fraction of human seminal plasma; $2.0 \mathrm{ml}$ seminal plasma supernatant of a man with normal sperm count $\left(39 \times 10^{6} / \mathrm{ml}\right)$ was chromatographed as described in 'Materials and Methods'. The column was calibrated with protein standards (Pharmacia, Piscataway, NJ) which are indicated in the figure as: Vo, blue dextran; $67, M_{\mathrm{r}} 67000$, bovine serum albumin; $43, M_{\mathrm{r}} 43000$, ovalbumin; $25, M_{\mathrm{r}} 25000$, chymotrypsinogen A; 13.7, $M_{\mathrm{r}} 13700$, ribonuclease A. (b) Zymography of the soluble portion of seminal plasma chromatographed in (a) and of aliquants of Fractions 45, 50, 57, 65, 70 and 75 from the column. Protein standards were electrophoresed in Lane St.; $10 \mu$ l soluble portion of seminal plasma were applied to the column in Lane $S$, and $37.5 \mu$ each of column Fractions (from a) 45, $50,57,65,70$ and 75 in the corresponding numbered lanes.

the proteinases did not change when zymograms were developed using Tris- $\mathrm{HCl}$ buffers in the $\mathrm{pH}$ range of 7-9 (data not shown). The presence of $\mathrm{Ca}^{2+}$ was required for their optimal activity and $\mathrm{Mg}^{2+}$ or $\mathrm{Mn}^{2+}$ were not able to substitute for it. Some activity was detected in the absence of added $\mathrm{CaCl}_{2}$; however, if $\mathrm{CaCl}_{2}$ was omitted and $5 \mathrm{~mm}$-EDTA added, these activities were not observed. The enzymic nature of these proteinase activities was further investigated by including different proteinase inhibitors in the Triton X-100 washes and the incubation buffer. Tranexamic acid, epsilon-aminocaproic acid and hydrocinnamic acid at 1, 5 or $50 \mathrm{~mm}$ concentrations were without effect on any proteolytic band of activity. The proteinase activities appeared to be substrate selective. Casein and gelatin hydrolysing activities were separated by chromatography of the soluble portion of seminal plasma on a Sephacryl S-200 HR gel filtration column. The majority of the proteinase activity towards casein was found at a molecular weight of about 35000 (Fig. 2a). The gelatin-degrading activities in this sample were $M_{\mathrm{r}} 50000$ or greater (no activities of $M_{\mathrm{r}} 34000$ and 37000 were detected) and they were separated from the caseinolytic activity in the column fractions (Fig. 2b). In addition, zymography of seminal plasma samples in casein-containing acrylamide gels demonstrated no proteinase activity (data not shown).

\section{Distribution of proteinase activities in subfractions of seminal plasma}

The proteinase activities appeared to be predominantly in the soluble portion of seminal plasma. The removal of membranous and particulate components of the plasma by 


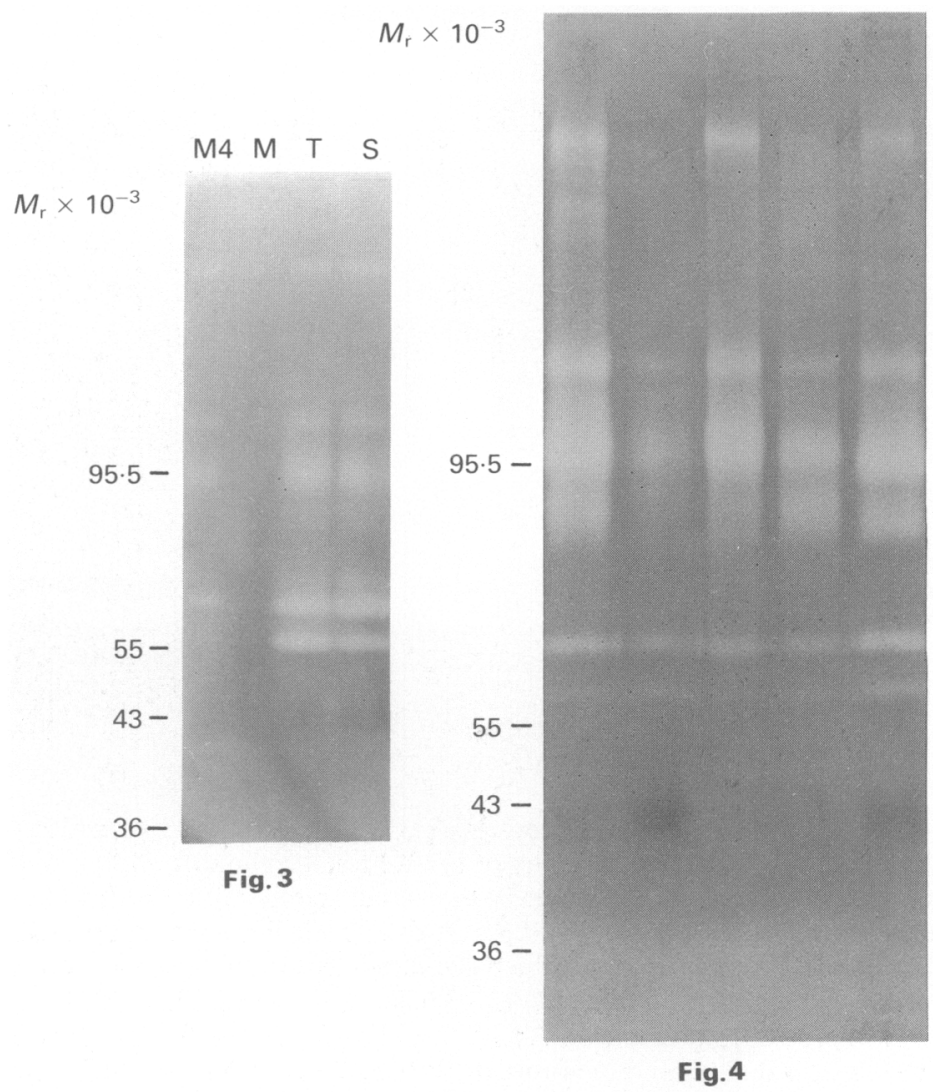

Fig. 3. Zymogram of total seminal plasma and the membrane and soluble fractions prepared from it. Semen from a vasectomized man was centrifuged in two steps as detailed in 'Materials and Methods'. Lane S contained $10 \mu$ of the soluble portion of seminal plasma, Lane T was $10 \mu \mathrm{l}$ of the total seminal plasma, Lane $M$ was the amount of membrane fraction equivalent to that in $10 \mu \mathrm{l}$ seminal plasma, and Lane M4 was the amount of membrane fraction 4 times that of $10 \mu \mathrm{l}$ seminal plasma.

Fig. 4. Proteinase zymogram of human prostatic fluids. Prostatic fluids $(10 \mu \mathrm{l})$ from 5 patients with chronic non-bacterial prostatitis were electrophoresed. Variation in the number of proteinase bands is demonstrated in these samples of prostatic secretion.

ultracentrifugation did not eliminate proteinase bands in the zymogram (Fig. 3). Conversely, when the membrane fraction was electrophoresed (an amount of membrane fraction equivalent to the membranous material in the volume of total seminal plasma applied to the gel), proteinase activity was barely detected. Electrophoresis of four times the amount of membranous material demonstrated proteinase bands of molecular size similar to that found in the soluble portion of the seminal plasma. This indicates that secretory granules in the membrane fraction contain these secretory enzymes or that proteinases in the soluble fraction of the plasma adhere to them.

\section{Tissue sources of proteinase activities}

The prostate gland appears to be a major source of most of these proteinase activities. Bands 1 and $2\left(M_{\mathrm{r}} 34000\right.$ and 37000$)$ were not found in prostatic secretion obtained by prostate massage (Fig. 4) but were present in the first 3 fractions of a split ejaculate (Fig. 5). However, proteinase activities of other molecular sizes were present in prostatic secretions. It is also apparent that 


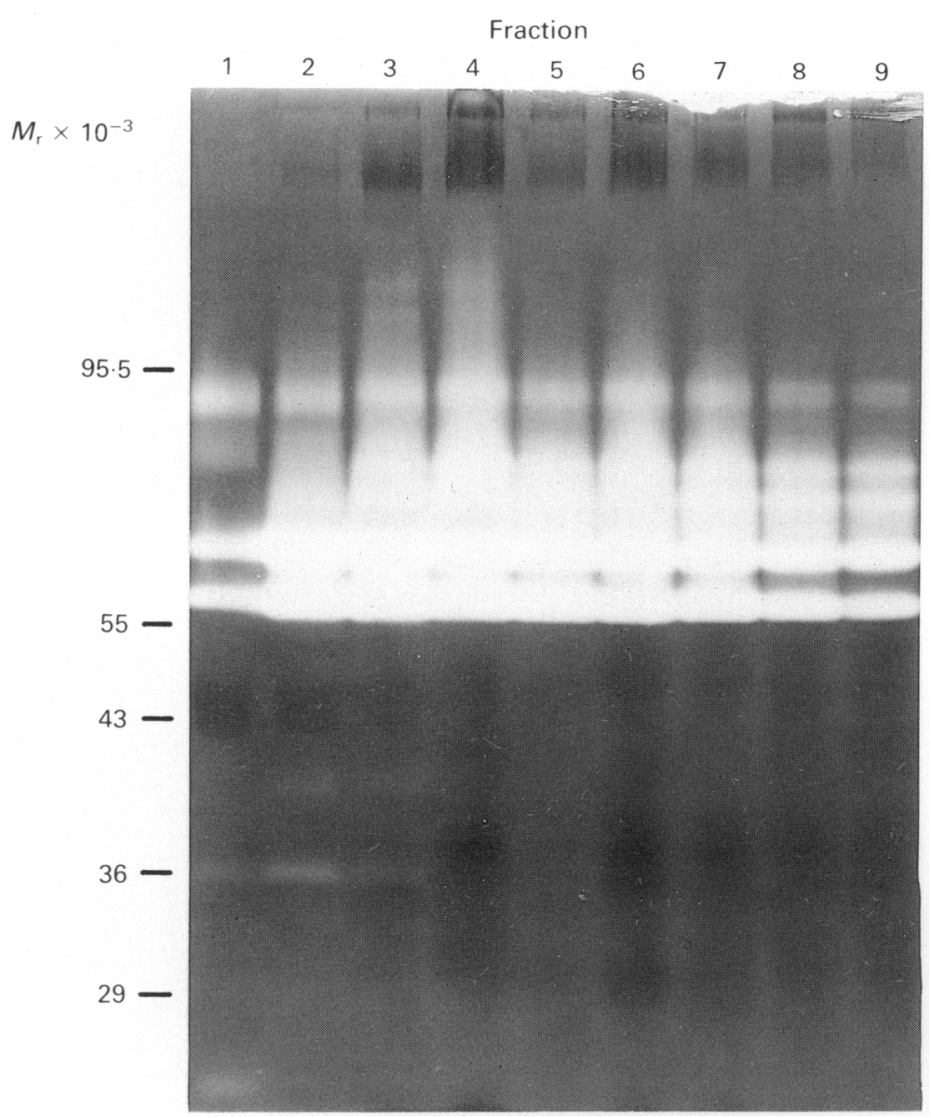

Fig. 5. Zymogram of proteinase activities in individual fractions of a split ejaculate. The semen sample of a man with a normal count of spermatozoa $\left(37 \times 10^{6} / \mathrm{ml}\right)$ was collected in 9 fractions. The seminal plasma of each fraction was prepared as described in 'Materials and Methods' and $7.5 \mu \mathrm{l}$ of each fraction were electrophoresed in the lanes so numbered.

there was a variation in the number of proteinase bands expressed in prostate secretion amongst individuals.

Proteinase activities were examined in aliquants of split ejaculates as another means to determine the possible sources of these proteinase activities. In this sample, a low molecular weight proteinase band was observed towards the bottom of the gel in Fraction 1. Band 2 was present only in the first three fractions of the ejaculate. The prominent Bands 3 and 4 were found in all fractions although they were more intense in Fractions 2-6. Bands 5 and 6 were found in Fraction 2 and subsequent fractions of the split ejaculate, but Band 5 was missing and Band 6 was much less intense in Fraction 1 than in Fraction 2. In distinction to the expression of Bands 5 and 6 , Band 7 was as intense in Fraction 1 as Fraction 2. Bands 8 and 9 were detected most intensely in Fractions $2-4$.

\section{Distribution of proteinase activities in seminal plasma from men with different semen properties}

The proteinase patterns in seminal plasmas of men who were normozoospermic, azoospermic, or who had semen with high viscosity were also examined. The number and relative activities of proteinase bands varied amongst individuals (Fig. 6). This variation was seen among men with 


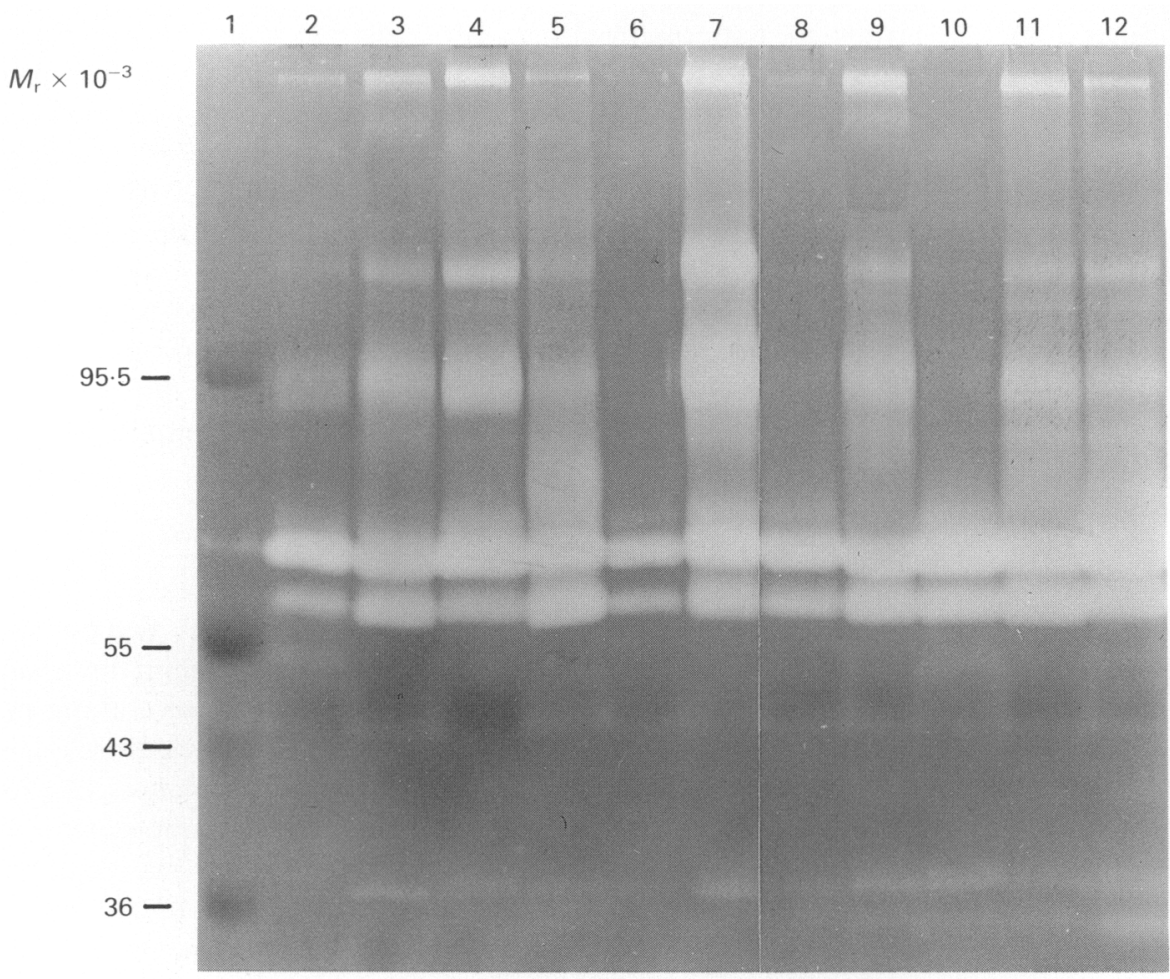

Fig. 6. Zymogram of seminal plasma from men with different numbers of spermatozoa and with different viscosities $(\mathrm{v}) ; 10 \mu \mathrm{l}$ of each seminal plasma sample was electrophoresed. Lane 1 , standards; Lane 2, no spermatozoa, $\mathrm{v}=+4-+5$; Lane 3, $10 \times 10^{6}$ spermatozoa/ml, coagulation present; Lane 4, $13 \times 10^{6}$ spermatozoa $/ \mathrm{ml}, \mathrm{v}=+4$; Lane 5 , no spermatozoa, $\mathrm{v}=+1$; Lane 6, no spermatozoa, $\mathrm{v}=0$; Lane $7,7 \times 10^{6}$ spermatozoa $/ \mathrm{ml}, \mathrm{v}=-1$; Lane 8 , $9 \times 10^{6}$ spermatozoa $/ \mathrm{ml}, \mathrm{v}=+1$; Lane $9,10 \times 10^{6}$ spermatozoa $/ \mathrm{ml}, \mathrm{v}=+1 ;$ Lane 10 , $121 \times 10^{6} \mathrm{spermatozoa} / \mathrm{ml}, \mathrm{v}=0 ;$ Lane $11,136 \times 10^{6}$ spermatozoa $/ \mathrm{ml}, \mathrm{v}=-1 ;$ Lane 12 , $65 \times 10^{6}$ spermatozoa $/ \mathrm{ml}, \mathrm{v}=0$.

Table 1. The expression of individual gelatinolytic proteinase activities in seminal plasma of men who were normozoospermic, oligozoospermic, azoospermic, or who had seminal plasma with elevated viscosity

\begin{tabular}{lcccccccccccccc}
\hline & & \multicolumn{10}{c}{ \% of samples expressing band $\sim M_{\mathrm{r}}\left(\times 10^{-3}\right)^{*}$} \\
\cline { 3 - 14 } Seminal plasma & No. & 34 & 37 & 60 & 66 & 71 & 82 & 90 & 105 & 110 & 120 & 140 & 158 \\
\hline Normozoospermic & 15 & 87 & 80 & 100 & 100 & 73 & 73 & 93 & 93 & 93 & 40 & 20 & 73 \\
Oligozoospermic & 21 & 24 & 10 & 100 & 100 & 71 & 52 & 81 & 81 & 52 & 19 & 14 & 81 \\
Azoospermic & 12 & 50 & 25 & 100 & 100 & 75 & 50 & 67 & 75 & 83 & 0 & 8 & 42 \\
Highly viscous $\dagger$ & 7 & 14 & 57 & 100 & 100 & 57 & 29 & 100 & 71 & 100 & 0 & 43 & 43 \\
\hline
\end{tabular}

*The zymogram for each sample was examined for the presence or absence of each proteinase band. These gels are qualitative only. They were not examined quantitatively since they were incubated to maximize activity of individual proteinase bands to optimize their detection. Each proteinase band would express its own enzymic rate of gelatin hydrolysis.

†These samples were liquefied within $1 \mathrm{~h}$, but demonstrated increased viscosity compared with normal samples.

sperm concentrations of $50 \times 10^{6} / \mathrm{ml}$ or greater (lanes $10-12$, Fig. 6), with oligospermia (lanes 4 and 7-9), with no spermatozoa (lanes 5 and 6), and with increased viscosity or coagulated particles 
present (lanes 2-4). The proteinase patterns from men with different semen characteristics were evaluated for the presence or absence of individual proteinase bands (Table 1). The proteinase activities of Bands 3 and $4\left(M_{\mathrm{r}} 60000\right.$ and 66000$)$ were found in all seminal plasmas examined whereas there was variation in the expression of the other molecular forms of proteinase, even in the normozoospermic group. Proteinases of $M_{\mathrm{r}} 34000,37000,82000$ and 120000 were detected more frequently in the normozoospermic samples than in those of oligozoospermic or azoospermic individuals. This would indicate that these forms of enzyme may arise from spermatozoa in the semen sample as well as from a glandular source. The proteinase activity of $M_{\mathrm{r}} \sim 120000$ (Band 10) was the only band missing entirely from azoospermic men. Semen samples from men with high semen viscosity but complete liquefaction within $1 \mathrm{~h}$ had a reduced frequency of proteinase bands in a pattern similar to that of the oligo- and azoospermic men. These samples with elevated viscosity commonly were oligospermic with respect to density of spermatozoa.

\section{Discussion}

The use of zymography with gelatin-containing SDS-polyacrylamide gels demonstrates the presence of several neutral-alkaline metallo-proteinase activities in human seminal plasma. Most of these activities in the ejaculate are generated by prostatic secretions but several are probably also derived from other sources such as the seminal vesicles, Cowper's and/or urethral glands and spermatozoa and/or epididymal fluid. These conclusions are based upon analysis of proteinase activities in expressed prostatic secretions, and split ejaculates and semen samples with different concentrations of spermatozoa. All proteinase activities were detected in expressed prostatic secretion except the $M_{\mathrm{r}} 34000$ and 37000 forms. The latter plus the $M_{\mathrm{r}} 82000$ and 120000 activities were observed more frequently in seminal plasma of normozoospermic men as compared with those of oligozoospermic or azoospermic individuals, thus implicating spermatozoa as a source of these 4 activities. The proteinase activities of $M_{\mathrm{r}} 60000,66000,71000$, and 82000 were prominent in nearly all fractions of the split ejaculate, indicating that these proteinase activities are probably derived from both the prostate and seminal vesicles and possibly spermatozoa. The $M_{\mathrm{r}} 37000$ and 90000 proteinases were found in the first 2-3 fractions, suggesting that the Cowper's/urethral glands and/or the prostate are a source of these activities. Similarly, proteinases of $M_{\mathrm{r}} 105000$ and 110000 were detected in Fractions 24 indicating their probable origin to be the prostate.

The identity of any of the gelatinolytic proteinase bands remains to be established. The majority of proteinase activities of $M_{\mathrm{r}} \sim 34000$ and 37000 detected in these studies may represent the sperminogen-spermin proteinase $\left(M_{\mathrm{r}} 30000-34000\right)$ of spermatozoa (Seigel et al., 1987; Hume et al., 1987), since the occurrence of these activities is greatly reduced in oligo- and azoospermic samples. However, some proteinase activities of the same molecular size may originate from another source since some azoospermic men do express such activities and evaluation of split ejaculates demonstrate its presence in the very first contractions of ejaculation. The absence of the $M_{\mathrm{r}} 34000$ and 37000 proteinase activities in prostatic secretion from men with chronic nonbacterial prostatitis could be due to diminished secretory activity (Wilson et al., 1984). However, the presence of the proteinase activities of the other molecular sizes in these samples would indicate otherwise, unless the absence of the $M_{\mathrm{r}} 34000$ and 37000 proteinase activities was specific for prostatitis.

Seminin $\left(M_{\mathrm{r}} 33000\right)$ can hydrolyse gelatin in addition to casein (Tauber \& Zaneveld, 1976). However, in a seminal fluid sample which lacked the $M_{\mathrm{r}} 34000$ and 37000 proteinase activities, there was no detectable gelatin hydrolysis in zymograms of those column fractions (peak of $\sim 35000$ ) which degraded casein (Fig. 2). This may indicate that seminin activity is not stable to treatment with SDS.

Some proteinase activities in seminal fluid have molecular masses close to those of well characterized metalloproteinases of human origin which hydrolyse gelatin. These include gelatinases of 
$M_{\mathrm{r}} 28000$ and 45000 from rheumatoid synovial fibroblasts (Okada et al., 1986); 72000 from gingiva (Nakano \& Scott, 1986); $120000-150000$ from skin (Seltzer et al., 1981); 225 000, 130000 and 90000 from neutrophils (Peppin \& Weiss, 1986); and 66000 Type IV collagenase of bronchial epithelium (Collier et al., 1988). However, any relationship of the seminal plasma gelatinolytic activities to these established proteinases remains to be determined. It is possibe that some proteinase activities expressed in the zymographs may be enzymically active proteolytic fragments or subunits of larger molecules. Conversely, some of the higher molecular weight proteinase activities may represent aggregates of proteinases or of proteins with proteinases since the SDS-polyacrylamide gels were run under non-reducing conditions.

The membranous organelles of prostatic origin in seminal plasma possess a zinc-dependent peptidase ( $\mathrm{pH}$ optimum 7.8 ) that cleaves synthetic peptide substrates designed for the measurement of elastase activities (Laurell et al., 1982). Unlike the proteinases detected in the gelatincontaining gels, this membrane peptidase is active in the presence of EGTA although inhibited by $o$-phenanthroline (Lilja \& Laurell, 1984). Most of the activities of gelatinolytic proteinases appear to be in the soluble portion of seminal plasma. The bands of proteolytic activity detected in membranous fractions of seminal plasma were of the same molecular size as those found in the soluble fraction. These membrane-associated activities could represent proteinases in secretory granules or other membranous components or enzyme simply adhering to these structures.

Semen coagulum liquefaction has been proposed to take place in three phases (Koren \& Lukac, 1979). The first phase is the solubilization of gelatinous materials. This phase can be inhibited by metals such as $\mathrm{Zn}^{2+}, \mathrm{Hg}^{2+}$ or $\mathrm{Cu}^{2+}$ (Koren \& Lukac, 1979) or $o$-phenanthroline and is insensitive to thiol agents or serine protease inhibitors (Lilja \& Weiber, 1984). The second phase is the degradation of solubilized coagulum proteins to peptides and this phase appears to be mediated by a variety of proteinases since it is inhibited by thiol reagents, $o$-phenanthroline and serine proteinase inhibitors (Lilja \& Weiber, 1984). The last phase is the hydrolysis of peptides to amino acids. The direct participation of these gelatinolytic proteinases in the semen liquefaction process remains to be established.

Seminal plasma has a qualitative effect on a number of sperm properties such as motility and viability (Eliasson et al., 1978) and can affect fertility (Check et al., 1989). A direct effect of seminal plasma proteinases upon sperm function has not been established although in the mouse, urokinase secreted by the vas deferens and seminal vesicle binds to spermatozoa upon ejaculation (Huarte et al., 1987). This selective proteinase is thus available for sperm surface interactions that would involve plasminogen in the female tract.

Increased viscosity of semen has been recognized as a reason for subfertility or infertility in men (Amelar, 1962; Bunge, 1970). Decreased activity of the chymotrypsin-like enzyme (seminin) of human seminal plasma (Lundquist et al., 1955) is correlated with poor semen liquefaction (Suominen et al., 1971; Tauber et al., 1980; Das \& Bhattacharyya, 1987) and it has been postulated to be the major proteinase in the initial phase of the liquefaction process. Analysis of seminal plasma samples with high viscosities but normal coagulum liquefaction does not show the absence of any band of gelatinolytic proteinase to be correlated with this condition. However, poor liquefaction is not the only reason for increased viscosity and these zymograms are qualitative in nature; that is, they are incubated to generate maximal detection of bands and are not adapted for strict quantitative comparisons.

Present work in our laboratory is to determine whether the gelatinolytic proteinases are able to hydrolyse the predominant proteins $\left(M_{\mathrm{r}} 52000,71000\right.$ and 76000$)$ of seminal vesicle secretion in semen (Lilja \& Laurell, 1984). Substantiation of this possibility would strongly support the role of these proteinases in semen liquefaction.

This research was supported in part by the General Research Funds of the Veterans Administration. 


\section{References}

Amelar, R.D. (1962) Coagulation, liquefaction and viscosity of human semen. J. Urol. 87, 187-190.

Amelar, R.D. \& Dublin, L. (1977) Semen analysis. In Male Infertility, pp. 105-140. Eds R. D. Amelar, L. Dubin \& P. C. Walsh. W. B. Saunders Co, Philadelphia.

Balerna, M., Colpi, G.M., Leonardi, D. \& Campana, A. (1984) Low molecular weight proteins in human seminal plasma electrophoretical evidence of their vesicular origin. Andrologia 16, 350-357.

Boonsaeng, V. (1986) Molecular structure of human seminal coagulum: the role of proteolysis. Andrologia 18, 252-258.

Bunge, R.G. (1970) Some observations on the male ejaculate. Fert. Steril. 21, 639-644.

Chaisitvanich, N. \& Boonsaeng, V. (1983) Molecular structure of human seminal coagulum: the role of disulfide bonds. Andrologia 15, 446-451.

Check, J.H., Winkel, C.A. \& Bollendorf, A. (1989) Addition of sperm free donor seminal plasma to low volume antegrade ejaculate in men with retrograde ejaculation. J. Androl. 10, P-21, abstr.

Collier, I.E., Wilhelm, S.M., Eisen, A.Z., Marmer, B.L., Grant, B.A., Seltzen, J.L., Kronberger, A., He, C., Bauer, E.A. \& Goldberg, G.I. (1988) H-ras oncogenetransformed human bronchial epithelial cells (TBE-1) secrete a single metalloprotease capable of degrading basement membrane collagen. J. biol. Chem. 263, 65796587.

Das, S.K.N. \& Bhattacharyya, A.K. (1987) Enzyme activities of human seminal plasma having different states of coagulation. Int. J. Fertil. 32, 86-89.

Eliasson, R., Arver, S., Johnsen, O., Kvist, U. \& Lindholmer, C. (1978) Some effects of human seminal plasma on the spermatozoa. Recent Progr. Androl. 14, 215-220.

Harvey, C. (1949) Fibrinolysin in human semen. A method of assay and some preliminary observations. Proc. Soc. Stud. Fertil. 1, 11-15.

Heussen, K.C. \& Dowdle, E.B. (1980) Electrophoretic analysis of plasminogen activators in polyacrylamide gels containing sodium dodecylsulfate and copolymerized substrates. Analyt. Biochem. 102, 186-202.

Hisazumi, H. (1970) Studies on the fibrinolytic activity in human semen studied by gel filtration. Invest. Urol. 7, 410-421.

Huarte, J., Belin, D., Basco, D., Sappino, A.-P. \& Vassalli, J.-D. (1987) Plasminogen activator and mouse spermatozoa: urokinase synthesis in the male genital tract and binding of the enzyme to the sperm cell surface. J. Cell Biol. 104, 1281-1289.

Hume, M.E., Siefel, M.S. \& Polakoski, K.L. (1987) Comparison between proteinase of human seminal plasma and of sperm origin. J. Androl. 8, 221-224.

Koren, E. \& Lukac, J. (1979) Mechanism of liquefaction of the human ejaculate. I. Changes of the ejaculate proteins. J. Reprod. Fert. 56, 493-499.

Laurell, C.B., Weiber, H., Ohlsson, K. \& Rannevik, G. (1982) A zinc-dependent peptidase in prostatic organelles present in seminal plasma. Clin. Chim. Acta 126, 161-170.

Liedholm, P., Astedt, B. \& Kullander, S. (1973) Passage of tranexamic acid (AMCA) to semen in man and its effects on the fibrinolytic activity and on migration of spermatozoa. Fert. Steril. 24, 517-520.

Lilja, H. (1985) A kallikrein-like serine protease in prostatic fluid cleaves the predominant seminal vesicle protein. J. clin. Invest. 76, 1899-1903.

Lilja, H. \& Laurell, C.B. (1984) Liquefaction of coagulated human semen. Scand. J. clin. Lab. Invest. 44, 447-452.

Lilja, H. \& Laurell, C.B. (1985) The predominant protein in human seminal coagulate. Scand. J. clin. Lab. Invest. 45, 635-641.

Lilja, H. \& Weiber, H. (1984) Synthetic protease inhibitors and post-ejaculatory degradation of human semen proteins. Scand. J. clin. Lab. Invest. 44, $433-438$.

Lowry, O.H., Rosebrough, N.H., Farr, A.L. \& Randall, R.J. (1951) Protein measurement with the Folin phenol reagent. J. biol. Chem. 193, 265-275.

Lukac, J. \& Koren, E. (1979) Mechanisms of liquefaction of the human ejaculate. II role of collagenase-like peptidases and seminal proteinases. J. Reprod. Fert. 56, 501-506.

Lundquist, F., Thorsteinsson, T. \& Buus, O. (1955) Purification and properties of some enzymes in human seminal fluid. Biochem. 59, 69-79.

Mann, T. \& Lutwak-Mann, C. (1981) Male Reproductive Function and Semen, pp. 31-32 \& 319-322. SpringerVerlag, New York.

McGee, R.S. \& Herr, J.C. (1987) Human seminal vesiclespecific antigen during semen liquefaction. Biol. Reprod. 37, 431-439.

McGee, R.S. \& Herr, J.C. (1988) Human seminal vesiclespecific antigen is a substrate for prostate-specific antigen (or P-30). Biol. Reprod. 39, 499-510.

Minakata, K., Asara, M. \& Yonekawa, O. (1986) Cysteine proteinase inhibitor levels in semen. Clin. Biochem. 19, 171-174.

Nakano, T. \& Scott, P.G. (1986) Purification and characterization of a gelatinase produced by fibroblasts from human gingiva. Biochem. Cell Biol. 64, 387-393.

Okada, Y., Nagase, H. \& Harris, E.D. (1986) A metalloproteinase from human rheumatoid synovial fibroblasts that digests connective tissue matrix components: purification and characterization. J. biol. Chem. 261, [4245-14255.

Peppin, G.J. \& Weiss, S.J. (1986) Activation of the endogenous metalloproteinase, gelatinase, by triggered human neutrophils. Proc. natn. Acad. Sci. USA 83, 4322-4326.

Rasmussen, J. \& Albrechtsen, O.K. (1960) Fibrinolytic activity in human seminal plasma. Fert. Steril. 11, 264-277.

Rui, H., Mevag, B. \& Purvis, K. (1984) Two-dimensional electrophoresis of proteins in various fractions of the human split ejaculate. Int. J. Androl. 7, 509-520.

Schiessler, H., Arnhold, M., Ohlsson, K. \& Fritz, H. (1976) Inhibitors of acrosin and granulocyte proteinase from human genital tract secretions. HoppeSeyler's Z. Physiol. Chem. 357, 1251-1260.

Schill, W.B. (1976) Quantitative determination of high molecular weight serum proteinase inhibitors in human semen. Andrologia 8, 359-364. 
Seigel, M.S., Bechtold, D.S., Willard, J.L. \& Polakoski, K.L. (1987) Partial purification and characterization of human sperminogen. Biol. Reprod. 36, 1063-1068.

Seltzer, J.L., Adams, S.A., Grant, G.A. \& Eisen, A.Z. (1981) Purification and properties of a gelatinspecific neutral protease from human skin. J. biol. Chem. 256, 4662-4668.

Suominen, J., Eliasson, R. \& Niemi, M. (1971) The relation of the proteolytic activity of human seminal plasma to various semen characteristics. J. Reprod. Fert. 27, 153-156.

Syner, F.N. \& Moghissi, K.S. (1972) Purification and properties of a human seminal protease. Biochem. $J$. 126, 1135-1140.

Syner, F.N., Moghissi, K.S. \& Yanez, J. (1975) Isolation of a factor from normal human semen that accelerates dissolution of abnormally liquefying semen. Fert. Steril. 26, 1064-1069.

Tauber, P.F. \& Zaneveld, L.J.D. (1976) Coagulation and liquefaction of human semen. In Human Semen and
Fertility Regulation in Men, pp. 153-166. Ed. E. S. E. Hafez. Mosby, St Louis.

Tauber, P.F., Propping, D., Schumacher, D.F.B. \& Zaneveld, L.F.D. (1980) Biochemical aspects of the coagulation and liquefaction of human semen. $J$. Androl. 1, 280-288.

Williams-Ashman, H.G., Beil, R.E., Wilson, J., Hawkins, M., Grayhack, J., Zunamon, A. \& Weinstein, N.K. (1980) Transglutaminases in mammalian reproductive tissues and fluids: relation to polyamine metabolism and semen coagulation. Adv. Enzyme Regul. 18, 239-258.

Wilson, M.J., Steer, R.C \& Kaye, K.W. (1984) Protein kinase activities in human prostatic secretion: biochemical characterization and effect of prostatitis. $J$. Lab. Clin. Med. 103, 905-911.

Wilson, M.J., Sinha, A.A., Powell, J.E.H. \& Estensen, R.D. (1988) Plasminogen activator activities in the developing rat prostate. Biol. Reprod. 38, 723-731.

Received 23 May 1989 